\title{
Humanização hospitalar com enfoque assistência de Enfermagem ao recém-nascido prematuro em Unidade de Terapia Intensiva Neonatal: uma revisão bibliográfica
}

\section{narrativa}

\author{
Hospital humanization with a focus on Nursing care for premature newborns in a Neonatal \\ Intensive Care Unit: a narrative literature review
}

Humanización hospitalaria con enfoque en la atención de enfermería para recién nacidos

prematuros en una Unidad de Cuidados Intensivos Neonatales: una revisión narrativa de la

literatura

Recebido: 02/11/2021 | Revisado: 10/11/2021 | Aceito: 14/11/2021 | Publicado: 23/11/2021

Camila Ribeiro Reis

ORCID: https://orcid.org/0000-0002-5564-9419

Universidade Ceuma, Brasil

E-mail: camribgf@gmail.com

Janayna Araújo Viana

ORCID: https://orcid.org/0000-0002-8855-5056

Universidade Ceuma, Brasil

E-mail: janaynavi@hotmail.com

Sâmia Marques Lopes

ORCID: https://orcid.org/0000-0002-3430-5350

Universidade do Amazonas, Brasil

E-mail: samiatocantins@gmail.com

Wlly Samara Costa Neves Soares

ORCID: https://orcid.org/0000-0003-3220-369X Faculdade de Imperatriz, Brasil

E-mail: wllysamara@outlook.com

Cristina Limeira Leite

ORCID: https://orcid.org/0000-0002-7321-1496

Universidade Ceuma, Brasil

E-mail: crislimeira@gmail.com

\begin{abstract}
Resumo
As Unidades de Terapia Intensiva (UTI), são ambientes complexos, com aparato de equipamentos e matérias, destinados a manutenção do cuidado a pacientes em estado grave. As Unidade de Terapia Neonatal (UTIN), são espaços destinados a atender bebês prematuro, com baixo peso ao nascer ou mesmo que nasceram com algum problema de saúde. Apesar desse ambiente, ser cercado de uma alta demanda de serviços, acaba exigindo rapidez e fluidez dos seus trabalhadores, por consequência o próprio atendimento se torna mecanizado. O presente estudo tem como objetivo, refletir sobre a importância da humanização no processo de cuidados na UTIN e sua importância para a qualidade da assistência prestada ao recém-nascido. Trata-se de uma revisão bibliográfica do tipo narrativa. Estudos evidenciam primordialmente o acolhimento humanístico como sendo um fator indispensável no meio hospitalar, e a inclusão da tríade familiar como abordagem no tratamento. Conclui-se que a humanização no cuidado se inicia como a escuta ativa tanto dos servidores em seus locais de trabalho como entre os profissionais e os pais dos pacientes, analisar os sinais, e expressões do paciente que possam auxiliar no melhor manuseio relacionado a higienização, mudança de decúbito, e assim, utilizar-se de métodos de conforto para criar um ambiente acolhedor ao recém-nascido e com a inclusão dos familiares sendo fundamental para a melhora no quadro clínico.
\end{abstract}

Palavras-chave: Terapia intensiva; Enfermagem neonatal; Humanização da assistência.

\begin{abstract}
The Intensive Care Units (ICU) are complex environments, with an apparatus of equipment and materials, intended for the maintenance of care for patients in serious condition. The Neonatal Care Units (NICU) are spaces designed to assist babies who are premature, with low birth weight or even those born with a health problem. Despite this environment, being surrounded by a high demand for services, it ends up demanding speed and fluidity from its workers, as a result, the service itself becomes mechanized. This study aims to reflect on the importance of humanization in the care process in the NICU and its importance for the quality of care provided to the newborn.
\end{abstract}


This is a literature review of the narrative type. Studies primarily show humanistic care as an indispensable factor in the hospital environment, and the inclusion of the family triad as an approach to treatment. It is concluded that humanization in care begins with active listening both from servers in their workplaces and between professionals and patients' parents, analyzing the signs and expressions of the patient that can help in better handling related to hygiene, changing position, and thus, using comfort methods to create a welcoming environment for the newborn and with the inclusion of family members being essential to improve the clinical condition.

Keywords: Intensive therapy; Neonatal nursing; Humanization of assistance.

\section{Resumen}

Las Unidades de Cuidados Intensivos (UCI) son ambientes complejos, con un aparato de equipos y materiales, destinados al mantenimiento de la atención de pacientes en estado grave. Las Unidades de Cuidados Neonatales (UCIN) son espacios diseñados para asistir a bebés prematuros, con bajo peso al nacer o incluso aquellos que nacen con algún problema de salud. A pesar de este entorno, al estar rodeado de una alta demanda de servicios, acaba exigiendo rapidez y fluidez a sus trabajadores, por lo que el propio servicio se mecaniza. Este estudio tiene como objetivo reflexionar sobre la importancia de la humanización en el proceso de atención en la UCIN y su importancia para la calidad de la atención brindada al recién nacido. Esta es una revisión de la literatura de tipo narrativo. Los estudios muestran principalmente el cuidado humanístico como un factor indispensable en el entorno hospitalario y la inclusión de la tríada familiar como abordaje del tratamiento. Se concluye que la humanización del cuidado comienza con la escucha activa tanto desde los servidores en sus lugares de trabajo como entre los profesionales y los padres de los pacientes, analizando los signos y expresiones del paciente que pueden ayudar en un mejor manejo relacionado con la higiene, el cambio de posición, y así, utilizando métodos de confort para crear un ambiente acogedor para el recién nacido y siendo fundamental la inclusión de los miembros de la familia para mejorar la condición clínica.

Palabras clave: Cuidados intensivos; Enfermería neonatal; Humanización de la atención.

\section{Introdução}

As Unidades de Terapia Intensiva (UTI), são ambientes complexos, com aparato de equipamentos e matérias, destinados a manutenção do cuidado a pacientes em estado grave. Nesse contexto, as UTIs, atendem pacientes de diversas faixas etárias, uma delas são as UTIs Neonatal, podendo ser chamadas também de Unidade de Terapia Intensiva Neonatal (UTIN), destinadas a atender bebês prematuro, com baixo peso ao nascer ou mesmo que nasceram com algum problema de saúde (Santos, 2021).

A hospitalização em uma UTIN, traz diversas consequências ao todos envolvidos nesse processo, de um lado a família, e do outro toda equipe atuante na UTIN. Assim, o cuidado prestado dentro desse ambiente, deve ser voltado não somente ao bebê que necessita de cuidados, mas também a família. Uma vez que, o nascimento de uma criança é um processo transformador dentro da família (Lucas et Al., 2009). Em recém-nascidos que necessitam de UTI logo após o nascimento, essa primeira vivência é quebrada, devido o momento, onde este necessita de dispositivos e equipamentos, necessários a manutenção de sua vida (Lohmann, 2011).

Com o passar dos anos e com a rotina vivenciada no ambiente UTI, as equipes que atuam nesse ambiente tentem a conviver com diversos estressores. Nesse contexto, á importante analisar como o trabalho dentro das UTIN, são organizados, e se isso influencia na qualidade da assistência prestada. Por se tratar de um ambiente complexo, repleto de equipamentos e instrumentos, a atuação do profissional deve ser o mais humanizado possível tornando-o mais acolhedor, uma vez que além de lidar com seres extremamente pequenos e delicados, tem que lidar também com a angústia dos pais e/ou familiares envolvidos (Wisniewski, 2020).

Nesse sentido, surgiu a Política Nacional de Humanização (PNH), em 2004, tendo como principal objetivo nortear as ações dos profissionais em saúde, pautada no modelo humanizado e holístico sobre o paciente. Haja visto que, muitas vezes devido a rotina que é imposta dentro dos serviços hospitalares, muitas vezes os profissionais passam a adotar uma postura mecânica e apática ao prestar o cuidar ao paciente. A partir, da implantação da PNH, houve avanços, no modelo de atenção e gestão do trabalho nas instituições de saúde. Visando assim, uma atenção centrada e voltada a atender as necessidades da população, além de promover também melhorias nas questões relacionada ao ambiente de trabalho e atendimento ao público 
(Reis et al., 2013).

Logo, dentre as funções exercidas pelos profissionais de saúde, está o acolhimento, pois desde a admissão na unidade ela está presente, com intuito de levantar informações sobre o paciente. No entanto, não deve seguir, um padrão robotizado de socialização e com o intuito de se manter uma conversa ativa e inter-relações no local de trabalho. A Política nacional de humanização, tendo em uma de suas bases a transversalidade, tendo como princípio a ampliação do contato interpessoal no ambiente hospitalar saindo da bola de hierarquização e isolamento pessoal (Brasil, 2013).

O presente trabalho tem como objetivo: refletir sobre a importância da humanização no processo de cuidados na UTIN e sua importância para a qualidade da assistência prestada ao recém-nascido. Trata-se de uma revisão bibliográfica do tipo narrativa. Visando refletir a prática da enfermagem mostrando os diversos fatores que norteiam as ações na UTI neonatal, e como os profissionais de enfermagem e os pais de RN's internados podem criar um ambiente acolhedor ao RN com a inclusão desses familiares e proporcionando um desenvolvimento e melhora significativa do quadro.

Nesse contexto, a importância de tal temática surgiu considerando que, se faz necessário o constante aprimoramento dos profissionais de enfermagem quanto as ações cuidadoras diretamente relacionadas aos pré-termos, e reflexão desses mesmos acerca da humanização no acolhimento dentro do atendimento hospitalar. Haja vista que o suporte ao prematuro deve ser ofertado bem-estar, tranquilidade, livre de estressores durante seus cuidados na terapia intensiva. Com base nisso espera-se que os resultados auxiliem a denotar as nuances do processo de enfermagem, impondo os enfermeiros como protagonista desse olhar holístico e reconhecer as prováveis falhas no atendimento e escutar e compreender as possíveis dificuldades encontradas pelas famílias acerca do entendimento relacionado ao tratamento terapêutico.

\section{Metodologia}

Trata-se de uma revisão bibliográfica do tipo narrativa. Nesse tipo de estudo, há liberdade quanto aos tipos de dados utilizados na pesquisa, não tendo restrição quanto as fontes. Logo, segundo Rother (2007, p. 1,): "Os artigos de revisão narrativa são publicações amplas, apropriadas para descrever e discutir o desenvolvimento ou o "estado da arte" de um determinado assunto, sob ponto de vista teórico ou contextual”. Para tanto, foi utilizado o que descreve, Estrela, (2018), para embasamento teórico do trabalho. Dessa forma estabeleceu-se a seguinte questão norteadora: Qual a importância da humanização no processo de cuidados na UTIN e sua importância para a qualidade da assistência prestada ao recém-nascido?

A primeira etapa consistiu na escolha do tema a ser pesquisado, norteando assim, a construção da revisão narrativa. $O$ tema elencado foi: Humanização hospitalar com enfoque assistência de Enfermagem ao recém-nascido prematuro em unidade de terapia intensiva neonatal. A segunda etapa consistiu na escolha e critérios utilizados, para a escolha dos textos e a delimitação dos descritores. A coleta de dados se deu nas bases de dados, Literatura Latino-Americana em Ciências de Saúde (LILACS), Scientific Eletronic Library Online (SCIELO) e Medline e no período de 2015 a 2020. Aos descritores foram aplicados os DeCS (descritores em ciências da saúde) um dicionário de organização de termos elaborado pela Bireme. Utilizou-se o operador de pesquisa AND e OR para o agrupamento dos seguintes descritores: Terapia Intensiva; Enfermagem Neonatal; Humanização da Assistência. Os critérios de inclusão foram: artigos publicados na língua portuguesa, texto disponível completo e publicados dentro do período de 5 anos. Os critérios de exclusão foram artigos indexados repetidamente e os que não atendam ao objetivo da pesquisa.

Foram empregadas algumas fases de elegibilidade dos artigos, e análise dos achados, para estabelecer quais artigos incluídos por meio de uma leitura prévia do objetivo, a fim de averiguar sua relação com o tema e posteriormente dar continuidade à leitura do artigo por completo na íntegra. Partindo dos resultados obtidos, foram selecionados 8 artigos científicos.

A seguir são apresentados os resultados do estudo desenvolvido. A Figura 1 apresenta o fluxograma de seleção de 
estudos do PRISMA correspondente as etapas de revisão da literatura, descrevendo todos os portais de consulta de artigos científicos utilizados no estudo e discriminando o processo de seleção do material analisado.

Figura 1 - Diagrama mostrando as etapas da revisão da literatura (fluxograma PRISMA, 2009).

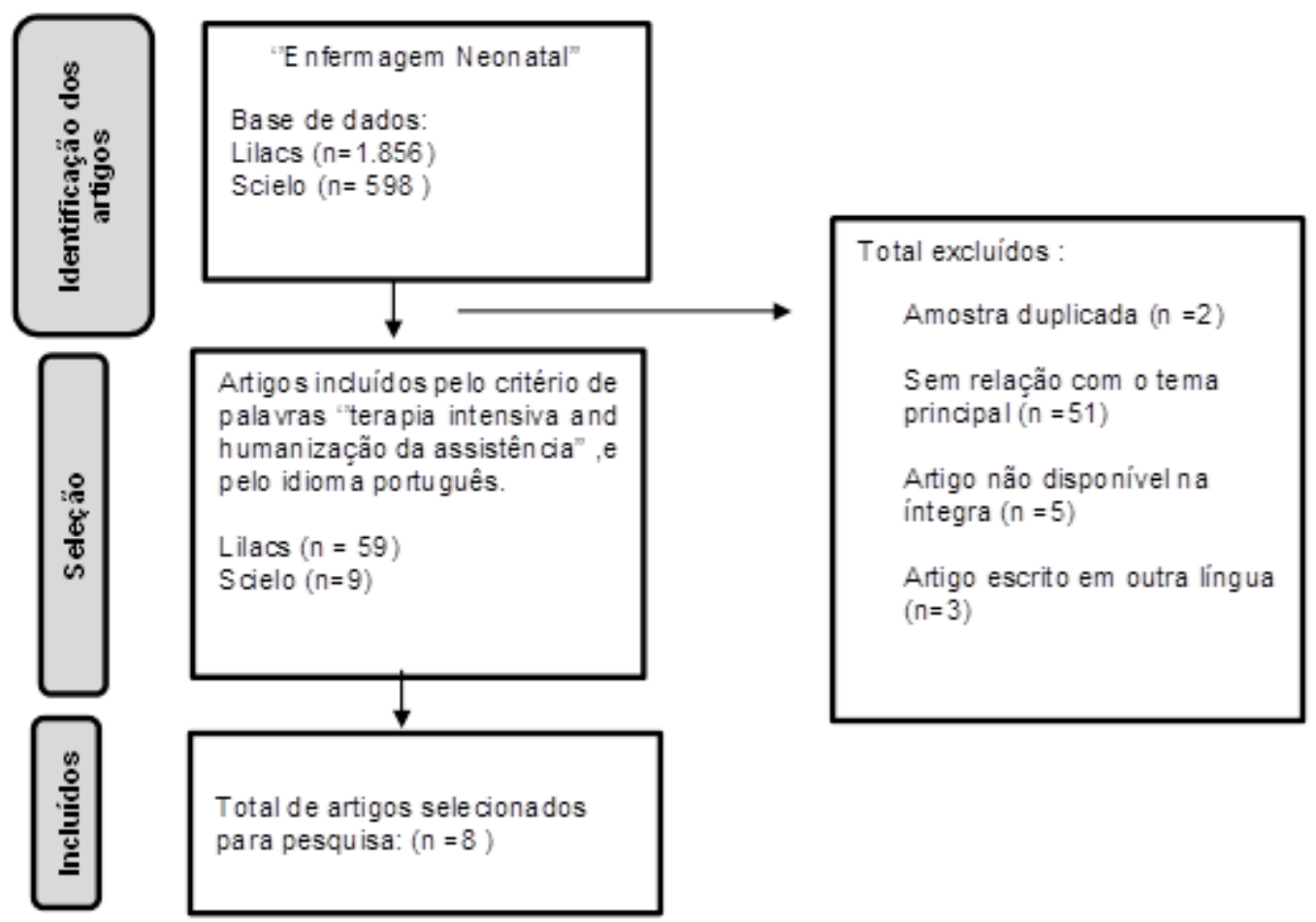

Fonte: Autores (2021).

\section{Resultados e Discussão}

No Quadro 1 a seguir são apresentadas as principais informações coletadas que identificam os artigos analisados a partir do ano de publicação, autores, título da pesquisa, e principais objetivos.

Quadro 1 - principais informações analisadas nos estudos selecionados.

\begin{tabular}{|c|c|c|c|c|c|}
\hline Autor & Ano & $\begin{array}{l}\text { Tipo de } \\
\text { Estudo }\end{array}$ & Título & Objetivo & Resultados \\
\hline $\begin{array}{l}\text { Soares; et. } \\
\text { al. }\end{array}$ & 2019 & $\begin{array}{c}\text { Artigo } \\
\text { Científico }\end{array}$ & $\begin{array}{l}\text { Percepção das } \\
\text { famílias sobre o } \\
\text { acolhimento no } \\
\text { contexto neonatal } \\
\text { durante um } \\
\text { processo de } \\
\text { intervenção }\end{array}$ & $\begin{array}{l}\text { Compreender a percepção } \\
\text { familiar sobre o acolhimento } \\
\text { no contexto da assistência em } \\
\text { enfermagem neonatal, antes e } \\
\text { após a implementação de um } \\
\text { protocolo de acolhimento. }\end{array}$ & $\begin{array}{l}\text { A compreensão das potencialidades e } \\
\text { fragilidades no processo de acolhimento, a } \\
\text { partir da perspectiva familiar possibilita a } \\
\text { transformação da realidade, propiciando } \\
\text { uma assistência pautada nas reais } \\
\text { necessidades da família e, portanto, mais } \\
\text { humanizada e qualificada. }\end{array}$ \\
\hline $\begin{array}{l}\text { Roseiro; } \\
\text { Paula }\end{array}$ & 2015 & $\begin{array}{c}\text { Artigo } \\
\text { Científico }\end{array}$ & $\begin{array}{l}\text { Concepções de } \\
\text { humanização de } \\
\text { profissionais em } \\
\text { Unidades de } \\
\text { Terapia Intensiva } \\
\text { Neonatal }\end{array}$ & $\begin{array}{l}\text { Compreender } \text { o cuidado } \\
\text { humanizado a partir do } \\
\text { resgate da perspectiva } \\
\text { afetiva, em oposição ao } \\
\text { modelo médico-tecnicista de } \\
\text { atenção à saúde, ou seja, com } \\
\text { ênfase nos aspectos } \\
\text { emocionais que envolvem } \\
\text { sua relação com o bebê e } \\
\text { com o trabalho em } \\
\text { Neonatologia. }\end{array}$ & $\begin{array}{l}\text { Os profissionais compreendem o cuidado } \\
\text { humanizado a partir do resgate da } \\
\text { perspectiva afetiva, em oposição ao } \\
\text { modelo médico-tecnicista de atenção à } \\
\text { saúde, ou seja, com ênfase nos aspectos } \\
\text { emocionais que envolvem sua relação com } \\
\text { o bebê e com o trabalho em Neonatologia. } \\
\text { A participação da família foi o aspecto } \\
\text { mais relevante para os profissionais, que } \\
\text { expressaram a importância da permanência } \\
\text { dos pais na unidade de terapia e sua } \\
\text { participação nos cuidados ao recém- } \\
\text { nascido. }\end{array}$ \\
\hline
\end{tabular}




\begin{tabular}{|c|c|c|c|c|c|}
\hline Reis; et. al. & 2013 & $\begin{array}{c}\text { Artigo } \\
\text { Científico }\end{array}$ & $\begin{array}{l}\text { Percepção da } \\
\text { equipe de } \\
\text { enfermagem sobre } \\
\text { humanização em } \\
\text { unidade de } \\
\text { tratamento } \\
\text { intensivo neonatal } \\
\text { pediátrica }\end{array}$ & $\begin{array}{l}\text { Identificar a percepção da } \\
\text { equipe de enfermagem sobre } \\
\text { a humanização no cuidado } \\
\text { em uma unidade de terapia } \\
\text { intensiva neonatal e } \\
\text { pediátrica }\end{array}$ & $\begin{array}{l}\text { A percepção da equipe de enfermagem } \\
\text { sobre humanização pauta-se na própria } \\
\text { ciência do cuidado de enfermagem e não } \\
\text { especificamente na PNH ou em mudanças } \\
\text { realizadas no serviço para a sua } \\
\text { implantação. }\end{array}$ \\
\hline $\begin{array}{l}\text { Oliveira; et } \\
\quad \text { al. }\end{array}$ & 2006 & $\begin{array}{c}\text { Artigo } \\
\text { Científico }\end{array}$ & $\begin{array}{l}\text { O processo de } \\
\text { trabalho da equipe } \\
\text { de enfermagem na } \\
\text { UTI neonatal e o } \\
\text { cuidar humanizado }\end{array}$ & $\begin{array}{l}\text { Diagnosticar o processo de } \\
\text { trabalho de enfermagem na } \\
\text { Unidade de Terapia Intensiva } \\
\text { Neonatal, identificando qual } \\
\text { a percepção da equipe sobre } \\
\text { seu objeto de trabalho, quais } \\
\text { são os instrumentos de } \\
\text { trabalho utilizados, qual é a } \\
\text { finalidade do trabalho, qual é } \\
\text { o produto obtido com o } \\
\text { trabalho e quais ações são } \\
\text { desenvolvidas para a } \\
\text { humanização da assistência } \\
\text { de enfermagem. }\end{array}$ & $\begin{array}{l}\text { Algumas medidas são adotadas como } \\
\text { forma de humanizar o cuidado, contudo } \\
\text { são parciais e isoladas, praticadas } \\
\text { individualmente. Quando a humanização } \\
\text { ocorre dessa forma, as diferenças } \\
\text { ressaltam aos olhos dos demais atores na } \\
\text { UTIN, ficando evidente a necessidade de } \\
\text { uma prática de natureza interdisciplinar, na } \\
\text { qual a humanização seja o princípio } \\
\text { norteador do planejamento e da assistência } \\
\text { desenvolvida para e com o recém-nascido } \\
\text { e sua família na UTIN. }\end{array}$ \\
\hline Lins; et. al. & 2013 & $\begin{array}{l}\text { Artigo } \\
\text { científico }\end{array}$ & $\begin{array}{l}\text { Percepção da } \\
\text { Equipe de } \\
\text { Enfermagem } \\
\text { acerca da } \\
\text { humanização do } \\
\text { Cuidado na UTI } \\
\text { Neonatal. }\end{array}$ & $\begin{array}{l}\text { Analisar a percepção da } \\
\text { equipe de Enfermagem } \\
\text { acerca da humanização do } \\
\text { cuidado ao recém- } \\
\text { nascido/RN de risco e } \\
\text { identificar ações dos } \\
\text { profissionais de Enfermagem } \\
\text { que contribuem para a } \\
\text { humanização do cuidado na } \\
\text { unidade de terapia intensiva } \\
\text { neonatal/UTIN. }\end{array}$ & $\begin{array}{l}\text { Destaca-se a importância de incluir a } \\
\text { família no cuidado ao bebê, com } \\
\text { implementação de ações de humanização } \\
\text { que depende do encontro envolvendo o } \\
\text { cuidador e o ser cuidado, tendo como } \\
\text { pressuposto a integralidade. }\end{array}$ \\
\hline $\begin{array}{l}\text { Nascimento, } \\
\text { et. al }\end{array}$ & 2013 & $\begin{array}{c}\text { Artigo } \\
\text { Científico }\end{array}$ & $\begin{array}{l}\text { Percepção e } \\
\text { atuação da equipe } \\
\text { de enfermagem } \\
\text { frente ao recém- } \\
\text { nascido pré-termo } \\
\text { desorganizado }\end{array}$ & $\begin{array}{l}\text { Descrever os sinais de } \\
\text { desorganização do recém- } \\
\text { nascido } \\
\text { identificados pela equipe de } \\
\text { enfermagem e a atuação } \\
\text { desta equipe raste } \\
\text { atendimento. }\end{array}$ & $\begin{array}{l}\text { Os resultados evidenciam uma equipe } \\
\text { capacitada a reconhecer os sinais de } \\
\text { desorganização emitidos pelo recém- } \\
\text { nascido e competente na adoção de } \\
\text { estratégias para sua homeostase. Concluiu- } \\
\text { se que a essência do cuidado ao recém- } \\
\text { nascido prematuro extrapola a técnica, } \\
\text { exigindo a observação da linguagem não } \\
\text { verbal expressada pelo neonato e } \\
\text { decodificação dos sinais que descrevem o } \\
\text { seu estado de estresse ou desorganização } \\
\text { para a implementação da assistência } \\
\text { adequada. }\end{array}$ \\
\hline $\begin{array}{l}\text { Mantelli, et } \\
\text { al. }\end{array}$ & 2017 & $\begin{array}{c}\text { Artigo } \\
\text { Científico }\end{array}$ & $\begin{array}{l}\text { Método Canguru: } \\
\text { Percepções da } \\
\text { equipe de } \\
\text { enfermagem em } \\
\text { terapia intensiva } \\
\text { pré-natal }\end{array}$ & $\begin{array}{l}\text { Conhecer a percepção da } \\
\text { equipe de enfermagem de um } \\
\text { hospital quanto à prática do } \\
\text { Método Canguru, } \\
\text { implementada durante a } \\
\text { internação de recém-nascidos } \\
\text { na Unidade de Tratamento } \\
\text { Intensivo Neonatal. }\end{array}$ & $\begin{array}{l}\text { Faz-se necessário qualificar a atenção ao } \\
\text { cuidado integral e humanizado ao recém- } \\
\text { nascido e sua família na UTIN. Novos } \\
\text { estudos com essa temática podem ser } \\
\text { realizados em serviços de saúde privados, } \\
\text { buscando vislumbrar possibilidades de } \\
\text { melhoria e implementação de práticas } \\
\text { baseadas em evidências recomendadas } \\
\text { pelas instituições governamentais. }\end{array}$ \\
\hline Leite et al. & 2020 & $\begin{array}{c}\text { Artigo } \\
\text { Científico }\end{array}$ & $\begin{array}{l}\text { Humanização da } \\
\text { assistência de } \\
\text { enfermagem em } \\
\text { unidade de terapia } \\
\text { Intensiva }\end{array}$ & $\begin{array}{l}\text { Compreender a humanização } \\
\text { da assistência de } \\
\text { enfermagem em unidade de } \\
\text { terapia intensiva neonatal de } \\
\text { hospital privado }\end{array}$ & $\begin{array}{l}\text { Percebeu-se uma preocupação dos } \\
\text { profissionais, em relação à importância do } \\
\text { envolvimento familiar no processo de } \\
\text { humanização, que perpassa pela confiança } \\
\text { mútua até o processo de empoderamento } \\
\text { gerado nos pais pela equipe. }\end{array}$ \\
\hline
\end{tabular}

Fonte: Autores (2021).

O processo de cuidar dentro das UTIN, são complexos e sistemáticos, os cuidados prestados no ambiente de terapia intensiva neonatal, trata-se de um local onde a atenção deve ser redobrada. Uma vez, que os pacientes ali internados, são seres 
extremamente frágeis, pequenos e delicados, exigindo assim, maior atenção e dedicação. Uma vez que se trata de pacientes que não são capazes de expressar o que sentem, nesse enfoque necessitam que a equipe esteja atenta, visando identificar suas necessidades com base na observação (Silva, 2019).

Nesse ambiente são realizados diversos procedimentos pela equipe multiprofissionais voltados para a uma melhor evolução do quadro clínico dos pacientes admitidos (Lohmann et al., 2017). Envolve desde a lavagem correta das mãos, ou como afirma Brasil (2017), procedimentos que entram em contato direto com o recém-nascido como a higiene, porém deve ser realizado poucas vezes e com o mínimo de cuidados para que a limpeza excessiva venha prejudicar a proteção natural da pele.

Nas UTIN, encontramos diversos equipamentos, todos com uma função especial, dentre eles estão inclusos a incubadora para manter o RN em uma temperatura agradável, monitores cardíacos, que informa qualquer alteração na frequência cardíaca, monitores respiratórios que mostram a capacidade respiratória do RN (Rodarte et al., 2019).

Para Nascimento et al (2013), o cenário real da UTIN, torna-se bastante conturbado não só para os visitantes como para os atuantes que frequentam por longos períodos de trabalho, e pode ser definido como barulhento, repleto e controlado por máquinas, a iluminação artificialmente presente, temperatura não adequada, um lugar onde exige a movimentação frequente do recém-nascido. Aspectos esse que vão afetar a evolução neurológica e moto do cliente, se manifestará em um paciente não organizado que se evidencia em taquicardia, apneia, hipotonia, estado de alerta ou completa exaustão, resultando em instabilidade das funções metabólicas, fisiológicas e comportamentais.

Com base em da Silva et. al., (2015) os cateteres que são essencialmente utilizados para tratamento medicamentoso sendo mais usado na administração de via endovenosa, suporte nutricional, sondagem gástrica, punção venosa, inserção de cateter epicutâneo, entre outros. O âmbito da terapia intensiva proporciona um ambiente contrário ao que o RN vivenciou na vida intrauterina, apesar dos avanços tecnológicos, não substituem a experiência humana que envolve diversos fatores importantes para um crescimento adequado (Roseiro; Paula, 2015).

Durante seus cuidados rotineiros, o profissional de enfermagem deve levar em conta a fragilidade física, atrelada as técnicas utilizadas, deve ser montar um plano de cuidados para o melhor atendimento, associando o melhor da tecnologia com o ao cuidado integral, em conjuntura a isso deve-se enfatizar a necessidade da assistência multidisciplinar de qualidade e humanizada, respeitando todos os seus limites éticos (Rolim; Cardoso, 2006; Reichert; Lins; Collet, 2009; Klein; Gaspardo; Linhares, 2011; Neves; Côrrea, 2009).

A Humanização em seu conceito está vinculada a empatia, que quer dizer, se colocar no lugar do próximo, entender os anseios e aflições, para que assim fique mais claro a visão do outro, de uma forma que seja entendida para ambos, e dessa forma compartilharem da mesma experiência (Reis et al., 2013). Humanização em UTI, torna-se o pilar de maior importância no contexto do cuidado, visando acolher e promover conforto. Considerando que, ter alguém internado numa UTI, traz consigo muitas angústias e inseguranças, nesse contexto, é de suma importância o acolhimento da família, sendo imprescindível durante todo processo, estes são corresponsáveis junto a equipe multiprofissional, pelo bom andamento da assistência prestada (Soares et al., 2019).

A Política Nacional de Humanização (PNH), veio trazer uma nova proposta, voltada a melhorar a qualidade do atendimento prestada nas unidades de saúde. Aliado, ao surgimento das tecnologias, que vieram com intuito de garantir a sobrevida dos pacientes internados em UTIs, no entanto sem perder a essência do cuidar e acolher o paciente, sem se deixar mecanizar (Brasil, 2005). Reconhecendo, que as diferentes especialidades e práticas de saúde, podem conversar com suas experiências, visando atender melhor o ser assistido. Juntos, esses saberes podem produzir saúde de forma mais corresponsável (Brasil, 2013).

Segundo Pagnano, (2020), os principais fatores que dificultam a humanização nas UTIN, são voltadas principalmente, a sobrecarga de atividades, quantitativo inadequado de profissionais, condições de trabalho inadequadas, ambiente de trabalho 
inadequado, além da baixa remuneração, forçando os profissionais a terem mais de um vínculo trabalhista, o que resulta da baixa qualidade da assistência.

Segundo Oliveira et al., (2006), outro ponto importante, diz respeito a saúde mental da equipe de enfermagem, onde diante dos aspectos relacionados a morte, estes, necessitam utilizar de mecanismo de defesas, para não adquirirem, transtornos emocionais e psíquicos, visto que sua participação no sofrimento do RN e família é frequente. Outros fatores, diz respeito a jornada de trabalho da equipe, onde devido à alta demanda de solicitações, necessitam, ficar por várias horas do expediente em pé, realizando movimentos repetitivos tais fatores, contribuem para a astenia, irritação, e desgaste mental.

Nessa perspectiva, os estudos de Mantelli, et al., (2017), analisaram a eficácia do Método Canguru, trata-se de uma estratégia humanizada, baseada nos princípios da atenção básica e da de assistência ao RN pré-termo, e tem como finalidade reduzir o tempo de distância entre a mãe e a criança. Os pais são orientados a ter o contato pele com pele diretamente com o bebê precocemente e a fazer a posição do canguru, os benefícios são inúmeros, dentre eles a construção de um bom relacionamento entre a tríade familiar e a equipe de saúde, aumenta as possibilidades da realização do aleitamento materno, e redução de índices de uma segunda internação consecutiva. Durante sua ação é estimulado a presença dos pais na unidade neonatal e a família participa ativamente dos cuidados recebidos ao recém-nascido, porém com alguns cuidados individualizados, respeitando o sono e o comportamento do RN.

Nesse aspecto Leite et al., (2020), incentiva à efetiva participação da mãe e do pai durante o período de internação inclui sua permanência junto ao seu filho. Isso revela um momento de amadurecimento da assistência neonatal, assumindo que o tratamento do RN envolve mais do que apenas a utilização de procedimentos e técnicas. Pretende-se, com isto, que sua história familiar e os cuidados que esta proporciona ao novo integrante da família permeiam os espaços da unidade neonatal.

Já Lins et al., (2013), ressalta que a interação entre os pais do RN e os profissionais são fundamentais para a adaptação da família, sendo responsabilidade do enfermeiro promover meios e traçar estratégias para que esse processo seja menos doloroso. Os pais consideram que a relação afetiva entre eles e a criança depende, de certa forma, da interação que existe entre a família e a equipe, pois, este grupo constitui um ponto de apoio, facilitando o contato entre pais e filho durante o período de internação.

\section{Considerações Finais}

Como resultados apresentados e diante da complexidade que envolve o cuidado em UTI e em específico nas UTIN, onde de um lado tem RN pré-maturo ou de baixo peso, famílias inseguras, e profissionais muitas vezes sobrecarregados das jornadas duplas de trabalho. A humanização é algo relevante e que vem a favorecer não somente aos RN's, mas também em toda equipe envolvida no cuidado. Com o intuito de proporcionar uma assistência humanizada ao lactente, uso de métodos utilizados como o canguru, contato pele com a mãe, essas ações criam laços afetivos e concedem um conforto para propiciar uma internação causa de menos danos psicológicos para ambos devido ao ambiente agitado e com vários equipamentos como é a unidade de terapia intensivista.

Contudo, para a efetivação da humanização, e tendo em vista, a sobrecarga de atividades, quantitativo inadequado de profissionais, condições e ambiente de trabalho inadequados, baixa remuneração, forçando os profissionais a terem mais de um vínculo trabalhista, o que resulta da baixa qualidade da assistência. Nota-se a importância da criação de uma estratégia que minimize tais aspectos, promovendo uma qualidade de bem-estar mental e físico aos trabalhadores.

O acolhimento, tanto do recém-nascido e seus pais na unidade de terapia intensiva, é essencial para fortalecer o elo afetivo entre eles melhorando a adaptação desse paciente a internação, essa inclusão auxilia na qualidade da assistência que está sendo prestada. Por outro lado, relatar aspectos essenciais a manutenção da vida do neonato, desde a monitorização, higiene corporal, administração de medicamentos, mobilização no leito, evolução no quadro clínico, são fundamentais, para 
assegurar a família a qualidade da assistência prestada. Utilizando de uma linguagem simples, onde a família consiga compreender todo o processo envolvido dentro do setor.

Como exemplos de meios utilizados para a assistência humanizada é o método canguru onde é estimulado ter o contato pele com pele entre o bebê e mãe, pois acalma o bebê e reduz o estresse, ajudando na adesão ao tratamento, correlacionando com as necessidades diretas do neonato, ou seja, tem a maior probabilidade de realização da amamentação onde o neonato vai começar a ser estimulado oralmente a realizar os movimentos de sucção e assim a mãe ira fortalecer esse vínculo afetivo por meio do aleitamento materno.

Foi notado a necessidade da abordagem do estudo voltada a esta temática, visando fornecer informações já existentes e contribui futuramente no aprimoramento da prática na enfermagem mostrando os diversos fatores que cerceiam a UTI neonatal, como os profissionais das enfermagem e os pais de RNs internados podem criar um ambiente acolhedor ao RN com a inclusão desses familiares e proporcionando um desenvolvimento e melhora significativa do quadro, pretendendo-se, portanto, a reflexão sobre as práticas de enfermagem utilizadas atualmente e sempre buscar a evolução positiva no processo de humanização do cuidado.

\section{Referências}

Brasil. (2013). Ministério da Saúde. Política Nacional de Humanização (PNH): documento base para gestores e trabalhadores do SUS. Ministério da Saúde.

Brasil. (2017). Ministério da Saúde. Secretaria de Atenção à Saúde. Departamento de Ações Programáticas Estratégicas. Atenção humanizada ao recémnascido: Método Canguru: manual técnico / Ministério da Saúde, Secretaria de Atenção à Saúde, Departamento de Ações Programáticas Estratégicas. (3a ed.), Ministério da Saúde.

da Silva, N. L. C., Queiroz, T. C. N., \& de Melo, M. D. C. B. (2015). Cuidando do Recém-nascido de Alto Risco. Folium Editorial. https://doi.org/10.5935/978-85-88361-95-9.2015b001

Estrela, C. (2018). Metodologia Científica: Ciência, Ensino, Pesquisa. Editora Artes Médicas.

Klein, V. C., Gaspardo, C. M., \& Linhares, M. B. M. (2011). Dor, autorregulação e temperamento em recém-nascidos pré-termo de alto risco. Psicologia: Reflexão e Crítica, 24, 504-512. https://doi.org/10.1590/s0102-79722011000300011

Leite, P. I. A. G., da Gama Pereira, F., Demarchi, R. F., Hattori, T. Y., do Nascimento, V. F., \& Terças-Trettel, A. C. P. (2020). Humanização da assistência de enfermagem em unidade de terapia intensiva neonatal. Revista de Enfermagem e Atenção à Saúde, 9(1). https://doi.org/10.18554/reas.v9i1.3649

Lins, R. N. P., Collet, N., Vaz, E. M. C., \& Reichert, A. P. (2013). Percepção da equipe de enfermagem acerca da humanização do cuidado na UTI Neonatal. Revista Brasileira de Ciências da Saúde, 17(3), 225-232. https://doi.org/10.4034/rbcs.2013.17.03.03

Lohmann, P. M. (2011). O ambiente de cuidado em UTI neonatal: a percepção dos pais e da equipe de saúde (Master's thesis). https://www.univates.br/bdu/handle/10737/213

Wisniewski, P. P. (2020). Síndrome de burnout no trabalho da enfermagem em unidade de terapia intensiva, centro cirúrgico e unidade de emergência: uma revisão integrativa da literatura. https://repositorio.unisc.br/jspui/handle/11624/3052

Pagnano, J. R. A. (2020). Gestão hospitalar humanizada: perspectiva dos profissionais de saúde em uma unidade de terapia intensiva neonatal (Doctoral dissertation).

Mantelli, G., Strapasson, M., Pierotto, A., Renosto, J., \& Silva, J. (2017). Método canguru: percepções da equipe de enfermagem em terapia intensiva neonatal. Revista de Enfermagem da UFSM, 7(1), 51 - 60.https://doi.org/10.5902/2179769221182

Nascimento, L. do, Rosa, A. C. de O., Lopes, C. A., Urzedo, J., Pacheco, Z. M. L., \& Salimena, A. M. de O. (2014). Percepção e atuação da equipe de enfermagem frente ao recém-nascido pré-termo desorganizado. Revista Baiana De Enfermagem27,(1). https://doi.org/10.18471/rbe.v27i1.6896

Neves, F. A. M., \& Corrêa, D. A. M. (2008). Dor em recém-nascidos: a percepção da equipe de saúde. Ciência, Cuidado e Saúde, 7(4), 461467.https://doi.org/10.4025/cienccuidsaude.v7i4.6626

Oliveira, B. R. G. D., Lopes, T. A., Viera, C. S., \& Collet, N. (2006). O processo de trabalho da equipe de enfermagem na UTI Neonatal e o cuidar humanizado. Texto \& Contexto - Enfermagem, 15(spe), 105-113. https://doi.org/10.1590/s0104-07072006000500012

Reichert, A. P. S., Lins, R. N. P., \& Collet, N. (2009). Humanização do cuidado da UTI neonatal. Revista Eletrônica de Enfermagem, 9. https://doi.org/10.5216/ree.v9i1.7148

Reis, L. S. D., Silva, E. F. D., Waterkemper, R., Lorenzini, E., \& Cecchetto, F. H. (2013). Percepção da equipe de enfermagem sobre humanização em unidade de tratamento intensivo neonatal e pediátrica. Revista Gaúcha de Enfermagem, 34, 118-124. 
Research, Society and Development, v. 10, n. 15, e199101522686, 2021

(CC BY 4.0) | ISSN 2525-3409 | DOI: http://dx.doi.org/10.33448/rsd-v10i15.22686

Rodarte, M. D. de. O., Fujinaga, C. I., Leite, A. M., Salla, C. M., Silva, C. G. d., \& Scochi, C. G. S. (2019). Exposição e reatividade do prematuro ao ruído em incubadora. CoDAS, 31. https://doi.org/10.1590/2317-1782/20192017233

Rolim, K. M. C., \& Cardoso, M. V. L. M. L. (2006). O discurso e a prática do cuidado ao recém-nascido de risco: refletindo sobre a atenção humanizada. Revista Latino-Americana de Enfermagem, 14, 85-92. https://doi.org/10.1590/s0104-11692006000100012

Roseiro, C. P., \& Paula, K. M. P. de. (2015). Concepções de humanização de profissionais em Unidades de Terapia Intensiva Neonatal. Estudos de Psicologia (Campinas), 32, 109-119.

Rother, E. T. (2007). Revisão sistemática X revisão narrativa. Rev.Acta Paulista de Enfermagem. 20(2), v-vi.

Santos, C. M. (2021). O trabalho do enfermeiro em Terapia Intensiva: um estudo etnográfico. https://repositorio.ufmg.br/handle/1843/38215

Silva, G. S. C. (2019). Humanização dos cuidados em Pediatria: Atuação do Enfermeiro Especialista em Enfermagem de Saúde Infantil e Pediatria (Doctoral dissertation).

Soares, L. G., Soares, L. G., das Neves Decesário, M., \& Higarashi, I. H. (2019). Perception of families on reception in the neonatal context during an intervention process/Percepção das famílias sobre o acolhimento no contexto neonatal durante um processo de intervenção. Revista de Pesquisa Cuidado é Fundamental Online, 11(1), 147-153. 